\title{
CORRELATION OF TOKUHASHI AND TOMITA SCORES WITH THE PROGNOSIS IN METASTATIC BREAST CANCER
}

\author{
CORRELAÇÃO DOS ESCORES DE TOKUHASHI E TOMITA COM O PROGNÓSTICO \\ EM TUMOR METASTÁTICO DE MAMA
}

\author{
CORRELACIÓN DE LAS PUNTUACIONES DE TOKUHASHI Y TOMITA COM \\ EL PRONÓSTICO EN TUMOR METASTÁSICO DE MAMA
}

Alexandre Henrique Silveira Bechara', Alberto Cliquet Junior ${ }^{1}$, Marcelo Ítalo Risso Neto', Ivan Guidolin Veiga', Wagner Pasqualini', Marcos Antônio Tebet ${ }^{1}$, Paulo Tadeu Maia Cavali', Elcio Landim ${ }^{1}$

1. Universidade Estadual de Campinas (UNICAMP), Department of Orthopedics and Traumatology, Campinas, SP, Brazil.

\begin{abstract}
Objective: The purpose of the present study was to evaluate the concordance between the Tokuhashi and Tomita scores with the prognosis of patients with vertebral metastases due to breast tumor, treated at the outpatient clinic of the Universidade Estadual de Campinas (UNICAMP). Methods: Twenty-nine patients with vertebral metastases from breast tumor were retrospectively evaluated. Twenty patients were surgically treated and received adjuvant therapy and only nine received conservative (chemotherapy/radiotherapy) or palliative/support treatment, depending on Tokuhashi and Tomita scores. Results: In this study, all selected patients were females with vertebral metastasis due to breast tumor; mean age of 57.6 years (SD = 11.8 years). The accuracy of the Tokuhashi scale was $62.1 \%$ and that of Tomita $72.4 \%$. In addition, the Tomita scale concentrates the majority of the patients' classifications for more than 12 months (69\%), indicating a good relation with the long-term prognosis (> 12 months). None of the evaluated characteristics - age or surgery - statistically influenced the survival of patients with primary breast tumor $(p>0.05)$. Conclusion: The Tokuhashi and Tomita scores showed good accuracy in relation to the prognosis of patients with spinal metastasis due to breast tumor.
\end{abstract}

Keywords: Spine; Breast neoplasms; Metastasis.

\section{RESUMO}

Objetivo: O objetivo do presente estudo é avaliar a concordância entre os escores de Tokuhashi e Tomita com o prognóstico das pacientes acometidas por metástases vertebrais por tumor de mama, atendidas no ambulatório da Universidade Estadual de Campinas (UNICAMP). Métodos: Foram avaliadas retrospectivamente 29 pacientes com metástases vertebrais de tumor de mama. Vinte pacientes foram tratadas com cirurgia e terapia adjuvante e apenas nove receberam tratamento conservador (quimioterapia/radioterapia) ou paliativo/suporte, dependendo dos escores de Tokuhashi e Tomita. Resultados: No estudo, foram selecionadas pacientes do sexo feminino acometidas por metástase vertebral decorrente de tumor de mama; média de idade de 57,6 anos (DP =11,8 anos). A acurácia da escala de Tokuhashi foi de 62,1\% e a de Tomita, 72,4\%. Além disso, a escala de Tomita concentra a maioria das classificações das pacientes do grupo por mais de 12 meses (69\%), indicando boa relação com o prognóstico a longo prazo (>12 meses). Nenhuma das características avaliadas - idade ou cirurgia - influenciou estatisticamente a sobrevida das pacientes com tumor primário de mama ( $p>0,05)$. Conclusão: Os escores de Tokuhashi e de Tomita apresentaram boa acurácia com relação ao prognóstico das pacientes acometidas por metástase na coluna vertebral decorrente de tumor de mama.

Descritores: Coluna vertebral; Neoplasias da mama; Metástase.

\section{RESUMEN}

Objetivo: El objetivo de este estudio es evaluar la concordancia entre las puntuaciones de Tokuhashi y Tomita con el pronóstico de las pacientes que tienen metástasis vertebrales por tumor de mama, tratadas en el ambulatorio de la Universidade Estadual de Campinas (Unicamp). Métodos: Se evaluaron retrospectivamente 29 pacientes con metástasis vertebrales por tumor de mama. Veinte pacientes fueron sometidas a tratamiento quirúrgico y terapia adyuvante y sólo nueve recibieron tratamiento conservador (quimioterapia/radioterapia) o paliativo/de apoyo, dependiendo de las puntuaciones de Tokuhashi y Tomita. Resultados: En el estudio, se seleccionaron pacientes del sexo femenino con metástasis vertebral derivada de tumor de mama; edad promedio de 57,6 años (DE = 11,8 años). La exactitud de la escala Tokuhashi fue del 62,1\% y la de Tomita, el 72,4\%. Además, la escala Tomita concentra la mayoría de las clasificaciones de las pacientes del grupo por más de 12 meses (69\%), lo que indica una buena relación con el pronóstico a largo plazo (> 12 meses). Ninguna de las características evaluadas - edad o cirugía - influenció estadísticamente la supervivencia de las pacientes con tumor primario de mama ( $p>0,05)$. Conclusión: Las puntuaciones de Tokuhashi y Tomita mostraron buena exactitud con relación al pronóstico de las pacientes que tienen metástasis de columna vertebral resultantes del tumor de mama.

Descriptores: Columna vertebral; Neoplasias de la mama; Metástasis. 


\section{INTRODUCTION}

Breast cancer is the most diagnosed malignant tumor and it is the second leading cause of death from cancer in the Western world. The incidence of breast cancer has continued to grow over the last few decades. In the United States in 2013, 230,000 new cases were diagnosed with the disease. ${ }^{1}$ Latin America has about 115,000 new cases of the disease each year and, of these, around 50,000 are reported in Brazil. ${ }^{2}$

Fortunately, the prognosis for patients with breast cancer has improved with advances in pharmacological therapy and surgical techniques to control the disease. As a consequence, the prevalence of breast cancer is increasing as the survival rate increases, causing breast cancer to become, in a way, a chronic disease condition. Although medical advances have improved the prognosis of patients with breast cancer, in contrast, the increase in survival increases the risk of progression to metastatic disease involving distant sites, such as bones, lungs, liver, and the brain. ${ }^{3}$

Approximately $20 \%$ of patients with breast cancer suffer from bone metastases. ${ }^{4}$ Most metastases occur in the thoracic spine (70\%), followed by the lumbar spine (20\%) and the cervical spine (10\%). Multiple non-contiguous metastases are found in 10\% to $38 \%$ of cases. Skeletal involvement is present in more than half the cases and spinal metastasis is one of the most frequently diagnosed tumors of this histological type. Involvement of the spine drastically reduces the quality of life of the patient due to the presence of pain and the risk of neurological compromise. ${ }^{5}$

Thus, it is important to investigate different strategies for pain relief, tumor reduction, and to correct the possible deformities resulting from pathological fractures of the vertebrae, avoiding spinal cord lesions. Therefore, to optimize treatment, patients with metastatic disease should have multidisciplinary follow-up involving gynecology, oncology, spine surgeons, and nuclear medicine. ${ }^{6}$

Currently, the therapeutic approaches to vertebral metastasis from breast cancer include chemotherapy, hormone therapy, bisphosphonates, radiotherapy, vertebroplasty/kyphoplasty, and decompression and spine stabilization surgery. These procedures are usually performed together with the goal of treating pain and the deformities caused by pathological fractures, ensuring stability, and protecting the neural elements.

The Tokuhashi et al. ${ }^{7,8}$ and Tomita et al. ${ }^{9}$ scores have been widely used to assess indications for surgery and predict the average survival of patients with metastatic spine disease. Thus, they guide the best therapeutic approach for this group of patients.

The objective of this study is to evaluate the concordance between the Tokuhashi and Tomita scores, which are used to estimate the survival of patients with metastatic spine disease, with the actual survival of patients with vertebral metastases from breast cancer treated at the outpatient clinic of the Universidade Estadual de Campinas (UNICAMP).

\section{METHODS}

Following release and exemption of the informed consent form by the Institutional Review Board of the Universidade Estadual de Campinas (UNICAMP), 29 patients with spinal metastases from breast cancer in follow-up at the Spine Surgery outpatient clinic of the Department of Orthopedics and Traumatology of UNICAMP were evaluated retrospectively. Of these, 20 had undergone surgery and adjuvant chemotherapy and/or radiotherapy and 9 had been treated only with adjuvant (chemotherapy end/or radiotherapy) or palliative/support therapy, according to the Tokuhashi et al. ${ }^{8}$ and Tomita et al. ${ }^{9}$ scores.

Included in this study were patients with spinal metastasis from breast cancer who were evaluated using radiography, computed axial tomography, and magnetic resonance of the entire spine, in addition to bone scintigraphy, and computed tomography of the thorax, abdomen, and skull. These tests were standardized for diagnosis and staging. Patients with incomplete medical records, in which the Tokuhashi ${ }^{8}$ and Tomita ${ }^{9}$ scores were not evaluated, were excluded. The minimum follow-up time was 1 year.
In this study, we used the revised Tokuhashi ${ }^{8}$ score developed to indicate the type of treatment for metastatic spinal lesions, taking the following criteria into account: 1. Overall condition of the patient, according to Karnofsky ${ }^{10}$ - poor, 0 points; moderate, 1 point; and good, 2 points; 2 . Number of extra-vertebral bone metastases - greater than or equal to three, 0 points; one or two, 1 point, and none, 2 points; 3. Number of vertebral metastases - greater than or equal to three, 0 points; two, 1 point; and one, 2 points; 4 . Resectability of metastases to major organs - not resectable, 0 points; resectable, 1 point; and none, 2 points; 5 . Primary tumor site - breast -5 points; and 6. Neurological deficit-complete, 0 points; incomplete, 1 point; and absent, 2 points (Table 1).

Tokuhashi et al. ${ }^{8}$ indicate the prognosis and the treatment option for these patients based on these indices: a) 0 to 8 points, prognosis of up to 6 months, conservative treatment; b) 9 to 11 points, prognosis 6 to 12 months, palliative treatment or excisional surgery in cases of a single lesion without metastases to major organs; c) 12 to 15 points, prognosis more than 1 year, treatment with excisional surgery (Table 2).

The score of Tomita et al. ${ }^{9}$ uses a score based on three prognostic factors: 1. Degree of malignity of the primary tumor in terms of growth (slow, 1 point; moderate, 2 points; and fast, 4 points); 2. Presence of visceral metastasis (without metastasis, 0 points; treatable, 2 points; untreatable, 4 points); and 3. Presence of bone metastasis (solitary or isolated, 1 point; multiple, 2 points). The total can vary from 2 to 10 points (Table 3 ).

According to Tomita et al., ${ }^{9}$ the treatment strategy is: a) 2 to 3 points, wide or marginal excision for long-term local control; b) 4 to 5 points, marginal or intralesional excision for medium-term local control; c) 6 to 7 points, palliative surgery for short-term control; and d) 8 to 10 points, non-surgical treatment (Table 4).

Table 1. Score of Tokuhashi et al. ${ }^{8}$

\begin{tabular}{|c|c|}
\hline Characteristic & Points \\
\hline \multicolumn{2}{|c|}{ 1. General condition (performance status) } \\
\hline Poor (PS 10\%-40\%) & 0 \\
\hline Moderate (PS 50\%-70\%) & 1 \\
\hline Good (PS 80\%-100\%) & 2 \\
\hline \multicolumn{2}{|l|}{ 2. Extra-vertebral metastases } \\
\hline$\geq 3$ & 0 \\
\hline $1-2$ & 1 \\
\hline 0 & 2 \\
\hline \multicolumn{2}{|l|}{ 3. Vertebral metastases } \\
\hline$\geq 3$ & 0 \\
\hline 2 & 1 \\
\hline 1 & 2 \\
\hline \multicolumn{2}{|l|}{ 4. Major organs metastases } \\
\hline Not removable & 0 \\
\hline Removable & 1 \\
\hline None & 2 \\
\hline \multicolumn{2}{|l|}{ 5. Primary site } \\
\hline Breast & 5 \\
\hline \multicolumn{2}{|l|}{ 6. Neurological deficit } \\
\hline Complete- Frankel A/B & 0 \\
\hline Incomplete- Frankel C/D & 1 \\
\hline Absent- Frankel E & 2 \\
\hline
\end{tabular}

Table 2. Prognosis and treatment according to Tokuhashi et al. ${ }^{8}$

\begin{tabular}{c|c|c}
\hline Result & Prognosis & Treatment \\
\hline 0 to 8 points & 6 months & Conservative \\
\hline 9 to 11 points & $6-12$ months & Palliative or excisional \\
\hline 12 to 15 points & More than 12 months & Excisional \\
\hline
\end{tabular}


Table 3. Score of Tomita et al. ${ }^{9}$

\begin{tabular}{c|c}
\hline & Score \\
\hline Primary tumor & 1 \\
\hline Breast (Slow growth) & \\
\hline Visceral metastasis & 0 \\
\hline Absent & 2 \\
\hline Treatable & 4 \\
\hline Untreatable & 1 \\
\hline Bone metastasis & 2 \\
\hline Solitary & \\
\hline Multiple &
\end{tabular}

Table 4. Prognosis and treatment according to Tomita et al. ${ }^{9}$

\begin{tabular}{c|c}
\hline Result & Treatment strategy \\
\hline 2-3 points & Wide or marginal excision, long-term control \\
\hline 4-5 points & $\begin{array}{r}\text { Marginal or intralesional excision, } \\
\text { medium-term control }\end{array}$ \\
\hline 6-7 points & Palliative surgery, short-term control \\
\hline 8-10 points & Non-surgical treatment \\
\hline
\end{tabular}

According to the study of Tomita et al., ${ }^{9}$ patients with scores of 2 or 3 points have an average survival of 38.2 months; of 4 or 5 points, an average survival of 21.5 months; of 6 or 7 points, an average survival of 10.1 months; and from 8 to 10 points, an average survival of 5.3 months. Therefore, to standardize the Tomita scale in relation to the Tokuhashi scale, patients with scores between 2 and 5 points have an average survival greater than 12 months, 6 or 7 points an average survival of 6 to 12 months, and between 8 and 10 points an average survival of less than 6 months.

In this way, the patients were categorized into three groups by score: Tokuhashi 0-8 points (Group 1), 9-11 points (Group 2), and 12-15 points (Group 3); Tomita 8-10 points (Group 1), 6-7 points (Group 2), and 2-5 points (Group 3). Similarly, the actual survival times of the patients were categorized into three groups: survival $<6$ months (Group 1), 6-12 months (Group 2), and survival $\geq 12$ months (Group 3). Thus, we evaluated the concordance of the Tokuhashi and Tomita scores categorized into groups with the group to which the actual survival time belonged.

\section{RESULTS}

After the selection and categorization of the patients, the accuracy between the expected Tokuhashi et $\mathrm{al}^{8}$. and Tomita et $\mathrm{al}^{9}$. intervals and the real survival groups were calculated, with 95\% confidence.

The average survival time of the patients was estimated using the Kaplan-Meier estimate, according to age group and whether or not surgery had been performed. The categories were compared using the log-rank test and because the median time of survival was impossible to calculate due to the low number of deaths in the defined categories, the average survival time was calculated.
The hazard ratios $(\mathrm{HR})$ for the respective categories were estimated with 95\% confidence using the Cox bivariate regression model and together with the Cox multivariate regression model to estimate the risk of death among the categories.

The tests were conducted with a level of significance of $5 \%$.

Table 5 shows that the average age of the patients with breast cancer metastasized to the spine was 57.6 years (SD $=11.8$ years) and that $69 \%$ of them underwent surgery.

Table 6 shows that the Tokuhashi score had an accuracy of $62.1 \%$ and the Tomita scale an accuracy of $72.4 \%$, a bit higher that the Tokuhashi scale in patients with primary breast cancer. Additionally, most of the patients (69\%) were classified in the $>12$ months group of the Tomita scale, indicating a good relationship with the real long-term survival (>12 months).

Figures 1 and 2 do not suggest any difference in the survival of patients with primary breast cancer in terms of age or whether or not surgery was performed.

Table 7 shows that none of the characteristics (age or surgery) evaluated significantly influenced the survival of the patients with primary breast cancer $(p>0.05)$.

\section{DISCUSSION}

The breast tumor is the most diagnosed histological type of cancer in women worldwide. Thus, it stands out at the main cause of cancer death in female patients. ${ }^{11}$

Breast cancer metastases have a predilection for bones, with a prevalence close to $69 \%$ in patients with advanced disease. ${ }^{12}$ The breast tumor has a particular affinity for spinal metastases, responsible for approximately two thirds of bone metastases discovered after diagnosis of the disease. Taking only spinal lesions into account, around a third become symptomatic, causing intractable pain, neurological deficit, mechanical instability due to pathological fractures, in addition to anemia and hypercalcemia. In the face of so many repercussions, breast cancer can cause severe deterioration in quality of life of these patients. ${ }^{13}$

The presence of bone metastases to the spine often indicates that the disease is at an advanced stage. However, with better adjuvant therapies, patients with metastatic disease are living for long periods of time after diagnosis. ${ }^{14}$

The treatment of these patients is many times complex and requires a multidisciplinary approach. The ideal treatment algorithm has not yet been defined and varies according to each patient.

Table 5. Description of the characteristics of the patients in the study.

\begin{tabular}{c|c}
\hline Variable & Description \\
\hline Age (years) & $57.6(11.8$ \\
\hline Average (SD) & \\
\hline Surgery, n (\%) & $9(31)$ \\
\hline No & $20(69)$ \\
\hline Yes &
\end{tabular}

Table 6. Description of actual survival of the patients and the survival according to the scales and the resulting accuracy of the scales.

\begin{tabular}{|c|c|c|c|c|c|c|c|c|c|}
\hline \multirow{3}{*}{ Scales } & \multicolumn{6}{|c|}{ Sobrevida } & & & \multirow{3}{*}{$\begin{array}{l}\text { Accuracy } \\
\text { (Cl 95\%) }\end{array}$} \\
\hline & \multicolumn{2}{|c|}{$<6$ months } & \multicolumn{2}{|c|}{6 to 12 months } & \multicolumn{2}{|c|}{$>12$ months } & \multicolumn{2}{|c|}{ Total } & \\
\hline & $\mathbf{n}$ & $\%$ & $\mathbf{n}$ & $\%$ & $\mathbf{n}$ & $\%$ & $\mathbf{n}$ & $\%$ & \\
\hline Tokuhashi & & & & & & & & & 62.1 \\
\hline$<6$ months & 4 & 13.8 & 0 & 0.0 & 1 & 3.4 & 5 & 17.2 & $(44.4 ; 79.8)$ \\
\hline 6 to 12 months & 0 & 0.0 & 0 & 0.0 & 7 & 24.1 & 7 & 24.1 & \\
\hline$>12$ months & 0 & 0.0 & 3 & 10.3 & 14 & 48.3 & 17 & 58.6 & \\
\hline Tomita & & & & & & & & & 72.4 \\
\hline$<6$ months & 1 & 3.4 & 0 & 0.0 & 0 & 0.0 & 1 & 3.4 & $(56.1 ; 88.7)$ \\
\hline 6 to 12 months & 0 & 0.0 & 0 & 0.0 & 2 & 6.9 & 2 & 6.9 & \\
\hline$>12$ months & 3 & 10.3 & 3 & 10.3 & 20 & 69.0 & 26 & 89.7 & \\
\hline Total & 4 & 13.8 & 3 & 10.3 & 22 & 75.9 & 29 & 100 & \\
\hline
\end{tabular}


The treatment options available include chemotherapy, hormone therapy, radiotherapy, and surgery. Because of good outcomes with radiotherapy, the use of this technique is recommended over surgical decompression. Even so, surgery continues to play a role in the treatment of metastatic spine tumors. ${ }^{15}$

Advances in surgical techniques and instrumentation have enabled more effective decompression and stabilization of the spine. In addition, today minimally invasive techniques, such as vertebroplasty or kyphoplasty can be used to treat pathological fractures in selected cases, avoiding very extensive surgical approaches that are traumatic

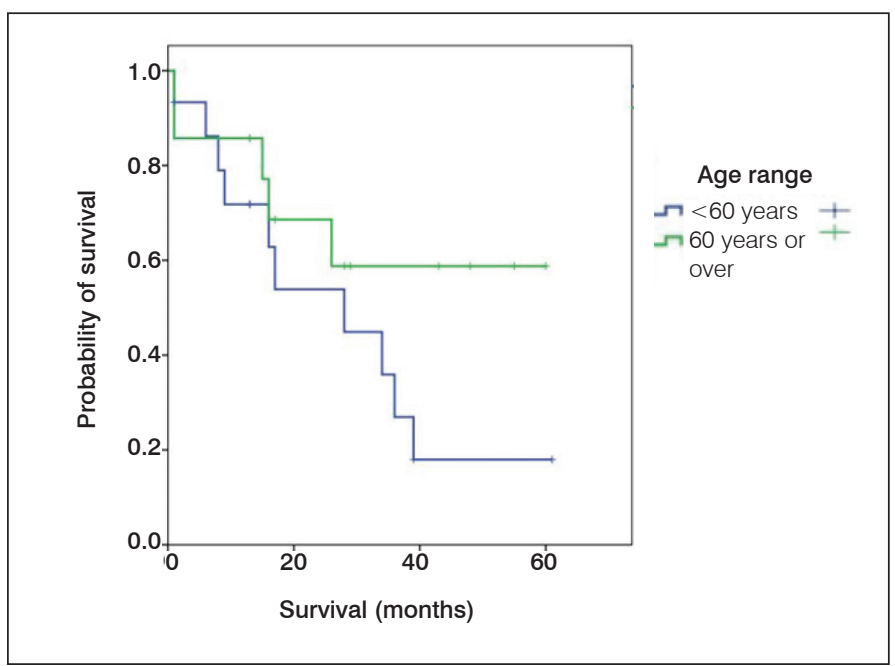

Figure 1. Kaplan-Meier estimate of patient survival by age range.

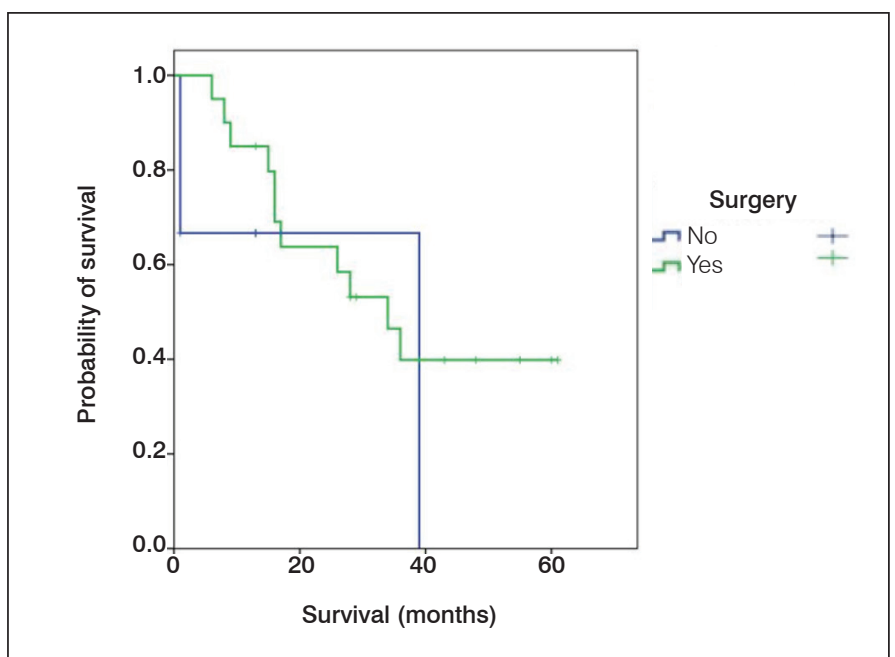

Figure 2. Kaplan-Meier estimate of patient survival according to whether they underwent surgery or not for a body already debilitated by the underlying disease and by strong chemotherapy drugs. ${ }^{16,17}$ In this study, there was no significant difference in survival time between the patients related to age or to the performance of surgeries. Patients older than sixty years of age had an average survival time of 40.61 months and those younger than sixty years of age averaged 27.92 months. In relation to surgery, patients who underwent surgery had an average survival of 36.37 months, while those who did not undergo surgery averaged 26.33 months. Therefore, treatment with radiotherapy and/or chemotherapy proved to be effective for the treatment of metastasized breast cancer. Thus, the indication of surgical procedures, often times more traumatic for patients, is avoided.

Several prognostic classifications are used to guide the treatment of patients with metastatic spine disease as to the best therapeutic option, among them are included Tokuhashi et al., ${ }^{7,8}$ Sioutos et al., ${ }^{18}$ Van der Linden et al., ${ }^{19}$ Tomita et al. ${ }^{9}$ and Bauer. ${ }^{20,21}$ In this study, we used the revised classification developed by Tokuhashi et al. $^{8}$ and the classification of Tomita et al. ${ }^{9}$

Tokuhashi et al. ${ }^{8}$ described a system to evaluate the prognosis of metastatic tumors of the spine based on six variables: the primary site of the tumor, the presence of absence of paralysis, the Karnofsky clinical performance status, ${ }^{10}$ the number of extra-spinal bone metastases, number of vertebral metastases, and major organ metastases.

These six factors are evaluated together producing values that range from 0 to 15 points, with 0 indicating the worst and 15 the best prognosis. (Table 2) It is interesting to note that Tokuhashi et al. ${ }^{8}$ consider neurological deficit to be an important prognostic factor of the disease. In our study, four patients had grade Frankel D neurological deficit as per the Frankel et al. scale, ${ }^{22}$ all of whom achieved complete recovery during treatment.

Tomita et al. ${ }^{9}$ studied some prognostic factors for tumor metastases in order to describe a system based on three factors: the rate of primary tumor growth, the number of bone metastases, and the number of visceral metastases. (Table 3)

These three factors are evaluated together, generating a score value that ranges from 2 - the best prognosis - to 10 points - the worst prognosis. (Table 4)

The site of the primary tumor is considered the most important prognostic factor by both the Tomita et al. ${ }^{9}$ and the Tokuhashi et al. ${ }^{8}$ scales. The study by Tokuhashi et al..$^{8}$ included 64 patients, 13 of whom had metastatic breast tumors. The study by Tomita et al. ${ }^{9}$ had a case series of 61 patients, 16 with breast tumors. ${ }^{23}$ According to Tomita et al., ${ }^{9}$ breast tumors have a low degree of malignity and metastases from this histological type permit longer survival. According to Tokuhashi et al., ${ }^{8}$ breast tumors are considered less aggressive, scoring 5 points and increasing the chances of patient survival.

This information is in agreement with our study, in that the patients had an average survival time of 33.69 months. Most of these patients $(n=22)$ were categorized by actual survival as group 3 (survival > 12 months).

Table 7. Estimate of the average survival times of patients according to the characteristics of interest and the results of comparative tests.

\begin{tabular}{|c|c|c|c|c|c|c|c|c|c|c|}
\hline \multirow{2}{*}{ Variable } & \multirow{2}{*}{$\begin{array}{l}\text { Mean estimated } \\
\text { time (months) }\end{array}$} & \multicolumn{2}{|c|}{ CI (95\%) } & \multirow{2}{*}{ HR } & \multicolumn{2}{|c|}{$\mathrm{Cl}(95 \%)$} & \multirow{2}{*}{ Deaths } & \multirow{2}{*}{ Total } & \multirow{2}{*}{$\%$} & \multirow{2}{*}{$p$} \\
\hline & & Lower & Upper & & Lower & Upper & & & & \\
\hline Age range & & & & & & & & & & 0.165 \\
\hline$<60$ years & 27.92 & 17.16 & 38.69 & 1.00 & & & 10 & 15 & 66.7 & \\
\hline 60 years or more & 40.61 & 27.22 & 54.00 & 0.48 & 0.16 & 1.40 & 5 & 14 & 35.7 & \\
\hline Surgery & & & & & & & & & & 0.311 \\
\hline No & 26.33 & 12.82 & 39.85 & 1.00 & & & 4 & 9 & 44.4 & \\
\hline Yes & 36.37 & 26.56 & 46.19 & 0.55 & 0.17 & 1.80 & 11 & 20 & 55.0 & \\
\hline Total & 33.69 & 24.66 & 42.71 & & & & 15 & 29 & 51.7 & \\
\hline
\end{tabular}


In their study of the analysis of the Tomita and Tokuhashi scores, Padalkar and Tow ${ }^{24}$ concluded that the Tomita score correlates better with real survival than the Tokuhashi score.

In our study, the Tokuhashi had accuracy of $62.12 \%$ and the Tomita score accuracy of $72.4 \%$, slightly higher than the Tokuhashi scale, in patients with primary breast tumors. In addition, the Tomita scale classified most patients in the $>12$ months group (69\%), indicating a good relationship with actual long-term survival (>12 months).

\section{CONCLUSION}

The Tokuhashi and Tomita scores have good accuracy in relation to the real survival of patients with breast cancer metastasized to the spine.

All authors declare no potential conflict of interest related to this article.

CONTRIBUTION OF THE AUTHORS: Each author made significant individual contributions to this manuscript. AHSB, ACJ, MIRN: main contributors. IGV,WP, MAT, PTMC, EL: manuscript review and intellectual contribution.

\section{REFERENCES}

1. DeSantis C, Ma J, Bryan L, Jemal A. Breast cancer statistics, 2013. CA Cancer J Clin. 2014;64(1):52-62

2. Lee $B L$, Liedke PE, Barrios $C H$, Simon $S D$, Finkelstein $D M$, Goss PE. Breast cancer in Brazil: present status and future goals. Lancet Oncol. 2012;13(3):e95-e102.

3. Siegel R, DeSantis $C$, Virgo K, Stein K, Mariotto A, Smith T, et al. Cancer treatment and survivorship statistics, 2012. CA Cancer J Clin. 2012:62(4):220-41

4. Coleman RE. Clinical features of metastatic bone disease and risk of skeletal morbidity. Clin Cancer Res. 2006;12(20 Pt 2):6243s-6249s.

5. Falicov A, Fisher CG, Sparkes J, Boyd MC, Wing PC, Dvorak MF. Impact of surgical intervention on quality of life in patients with spinal metastases. Spine (Phila Pa 1976). 2006;31(24):2849-56.

6. Chan-Seng E, Charissoux M, Larbi A, Tétreau R, Gerber YN, De Verbizier-Lonjon D, et al. Spinal metastases in breast cancer: single center experience. World Neurosurg. 2014:82(6):1344-50

7. Tokuhashi Y, Matsuzaki H, Toriyama S, Kawano H, Ohsaka S. Scoring system for the preoperative evaluation of metastatic spine tumor prognosis. Spine (Phila Pa 1976). 1990:15(11):1110-3.

8. Tokuhashi $Y$, Matsuzaki $H$, Oda H, Oshima M, Ryu J. A revised scoring system for preoperative evaluation of metastatic spine tumor prognosis. Spine (Phila Pa 1976). 2005;30(19):2186-91.

9. Tomita K, Kawahara N, Kobayashi T, Yoshida A, Murakami H, Akamaru T. Surgical strategy for spinal metastases. Spine (Phila Pa 1976). 2001;26(3):298-306

10. Karnofsky DA, Young CW. Comparative aspects of the pharmacology of the antimetabolites. Fed Proc. 1967:26(4):1139-45.

11. Warner E. Clinical practice. Breast-cancer screening. N Engl J Med. 2011;365(11):1025-32.

12. Coleman RE, Rubens RD. The clinical course of bone metastases from breast cancer. $\mathrm{Br}$ J Cancer. 1987;55(1):61-6.

13. Briasoulis $E$, Karavasilis V, Kostadima L, Ignatiadis M, Fountzilas G, Pavlidis N. Metastatic breast carcinoma confined to bone: portrait of a clinical entity. Cancer. 2004;101(7):1524-8.

14. Choi D, Crockard A, Bunger C, Harms J, Kawahara N, Mazel C, et al. Review of metastatic spine tumour classification and indications for surgery: the consensus statement of the Global Spine Tumour Study Group. Eur Spine J. 2010:19(2):215-22.

15. Quraishi NA, Gokaslan ZL, Boriani S. The surgical management of metastatic epidural compression of the spinal cord. J Bone Joint Surg Br. 2010;92(8):1054-60.

16. Alvarez L, Pérez-Higueras A, Quiñones D, Calvo E, Rossi RE. Vertebroplasty in the treatment of vertebral tumors: postprocedural outcome and quality of life. Eur Spine J. 2003;12(4):356-60.

17. König MA, Jehan S, Balamurali G, Bierschneider M, Grillhösl A, Boszczyk BM. Kyphoplasty for lytic tumour lesions of the spine: prospective follow-up of 11 cases from procedure to death. Eur Spine J. 2012;21(9):1873-9.

18. Sioutos PJ, Arbit E, Meshulam CF, Galicich JH. Spinal metastases from solid tumors. Analysis of factors affecting survival. Cancer. 1995;76(8):1453-9.

19. van der Linden YM, Dijkstra SP, Vonk EJ, Marijnen CA, Leer JW; Dutch Bone Metastasis Study Group. Prediction of survival in patients with metastases in the spinal column: results based on a randomized trial of radiotherapy. Cancer. 2005:103(2):320-8.

20. Bauer H, Tomita K, Kawahara N, Abdel-Wanis ME, Murakami H. Surgical strategy for spinal metastases. Spine (Phila Pa 1976). 2002;27(10):1124-6.

21. Bauer HC, Wedin R. Survival after surgery for spinal and extremity metastases. Prognostication in 241 patients. Acta Orthop Scand. 1995:66(2):143-6.

22. Frankel HL, Hancock DO, Hyslop G, Melzak J, Michaelis LS, Ungar GH, et al. The value of postural reduction in the initial management of closed injuries of the spine with paraplegia and tetraplegia. I. Paraplegia. 1969;7(3):179-92.

23. Shehadi JA, Sciubba DM, Suk I, Suki D, Maldaun MV, McCutcheon IE, et al. Surgical treatment strategies and outcome in patients with breast cancer metastatic to the spine: a review of 87 patients. Eur Spine J. 2007;16(8):1179-92.

24. Padalkar P, Tow B. Predictors of survival in surgically treated patients of spinal metastasis. Indian J Orthop. 2011;45(4):307-13. 